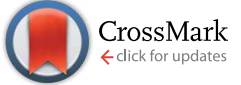

Cite this: J. Mater. Chem. A, 2015, 3 , 13986

Received 27th October 2014 Accepted 18th May 2015

DOI: 10.1039/c4ta05749j

www.rsc.org/MaterialsA

\section{EM shielding effectiveness of Pd-CNT-Cu nanocomposite buckypaper $\dagger$}

\author{
Anil Kumar, ${ }^{a}$ Avanish Pratap Singh, ${ }^{a}$ Saroj Kumari, ${ }^{a}$ A. K. Srivastava, ${ }^{\text {a }}$ Sivaiah Bathula, ${ }^{a}$
} S. K. Dhawan, ${ }^{a}$ P. K. Dutta ${ }^{b}$ and Ajay Dhar*a

We report the synthesis of a nanocomposite consisting of Pd doped multiwall carbon nanotubes decorated with Cu nanoparticles, as a lightweight and flexible microwave absorbing material, using an electroless technique. The synthesised nanocomposite was extensively characterized by employing X-ray diffraction, Raman spectroscopy, FESEM, and HRTEM and their results were correlated with the high electromagnetic interference (EMI) shielding observed in the present study. The optimum dielectric properties coupled with good electrical conductivity of this nanocomposite contribute to designing this absorption-based microwave shield, which exhibited a good EMI shielding effectiveness (EMI SE) of 35 $\mathrm{dB}$ at a thickness of $200 \mu \mathrm{m}$, resulting in a high specific EMI SE of $\sim 108 \mathrm{~dB} \mathrm{~cm}^{3} \mathrm{~g}^{-1}$ in the Ku-band.

\section{Introduction}

Electromagnetic interference (EMI) has received worldwide social and scientific attention due to the extensive use of electronic and communication gadgets. ${ }^{1-3}$ Serious problems of EMI are generally encountered in satellite communication, radar surveillance systems, digital devices, wireless technology and other sophisticated electronic equipment. ${ }^{1,3}$ Besides this, EMI in daily life is also known to incur harmful effects under certain environments. ${ }^{4}$ This novel sort of pollution has triggered the use of efficient counter-measures to ensure the optimum performance of electronic gadgets in the presence of EM noise, ${ }^{5}$ especially for aircraft and aerospace applications. As lightweight and flexibility are essential considerations, especially for aircraft and aerospace applications, enormous efforts are presently underway for developing a suitable EMI shielding material on an industrial scale. ${ }^{6}$ Light weight carbon-based polymer composites have been reported to possess high EMI shielding along with excellent mechanical properties with large flexibility in their aspect ratio. ${ }^{7}$ Several such studies have been reported employing different polymer reinforced carbon composites $^{8}$ but they suffer from the inherent problems of low melting temperature and low temperature degradation characteristics, ${ }^{9}$ which make them unsuitable for most of the applications.

\footnotetext{
${ }^{a}$ Material Physics and Engineering Division, CSIR-National Physical Laboratory, Dr K. S. Krishnan Marg, New Delhi-110012, India. E-mail: adhar@nplindia.org; Fax: +9111-25726938; Tel: +91-11-45609456

${ }^{b}$ Department of Chemistry, MN National Institute of Technology, Allahabad-211 004, India

$\dagger$ Electronic supplementary information (ESI) available. See DOI: 10.1039/c4ta05749j
}

Composites, based on different forms of highly conducting carbon, such as carbon nanotubes, ${ }^{\mathbf{1 0}}$ graphene, ${ }^{\mathbf{1 1}}$ and carbon foam,${ }^{12,13}$ have been reported to achieve high EMI shielding and the shielding effectiveness (SE) of these polymer composites is found to decrease as per the following order: multiwall carbon nanotubes (MWCNTs) > graphene $>$ carbon foam $>$ carbon nano-fibers $>$ carbon black. ${ }^{\mathbf{1 4}}$ The EMI SE of the polyaniline composite with $\mathrm{Ag}$ decorated (5.0 wt\% loading) graphene was reported to be $29.33 \mathrm{~dB},{ }^{15}$ which was attributed to the enhancement in electrical conductivity due to metal particle decoration and high permittivity of these composites, and it was observed that absorption was the governing factor for the improved EMI shielding. Shinn-Shuong et al. ${ }^{16}$ have reported an EMI shielding of $\sim 30 \mathrm{~dB}$ in $\mathrm{Cu} / \mathrm{Ni}$ coated fiber reinforced composites, developed by an electroless technique.

In the same order, CNT based composites, apart from being lightweight, exhibit good electrical conductivity and mechanical flexibility with high EMI shielding. ${ }^{17}$ However, the decoration of metal particles on these nano-sized matrices could further expand their potential as excellent EMI shielding materials due to the increase in their charge carrier density. ${ }^{18}$ Such metal nanoparticle decorated composites could provide distinctive advantages over conventional EMI shielding materials as they exploit the combined properties of both the components, i.e., excellent electrical and thermal conductivities of the metal with a low thermal expansion coefficient and corrosion-resistive properties of the CNTs. ${ }^{19}$ Thus, metal nanoparticle decoration on MWCNTs could be a novel and an economical idea for EMI shielding applications. In this direction, we have previously reported $^{20}$ a fabrication method for high strength carboncopper $(\mathrm{C}-\mathrm{Cu})$ composites from a polyaromatic hydrocarbon based carbon copper nanocomposite synthesized using an electroless technique, which possess a very good EMI shielding 
of $\sim 58 \mathrm{~dB}$ with a low reflection of $\sim 12.5 \mathrm{~dB}$ at a sample thickness of $2 \mathrm{~mm}$. Some techniques that have been so far employed for the decoration of metal nanoparticles on MWCNTs include impregnation, ${ }^{21}$ electroless metal-plating, ${ }^{22}$ self-assembly, ${ }^{23}$ electrodeposition, ${ }^{24}$ physical vapor deposition, ${ }^{25}$ etc. Despite the good EMI shielding characteristics of highly conducting materials, such as carbon nanotubes and other exotic forms of carbon, ${ }^{26}$ only a few attempts ${ }^{27,28}$ have been made to introduce metals along with MWCNTs for enhancing the shielding effectiveness. However, W. Zhao et al. reported silver nanoparticle decorated CNTs by an in situ photochemical reduction method with a good EMI shielding. ${ }^{29}$ However, due to their cost they may not be a commercial material.

In the present study, we demonstrate the synthesis of a costeffective $\mathrm{Cu}$ nanoparticle decorated Pd doped MWCNT derived $\mathrm{C}-\mathrm{Cu}$ nanocomposite buckypaper ${ }^{29}$ (thickness $=200 \mu \mathrm{m}$ ) as an efficient EMI shielding material employing an electroless technique. This technique, based on simple chemical reduction chemistry, is a fast and reproducible synthesis technique, wherein the synthesis of $\mathrm{Cu}$ nanoparticles and their decoration on MWCNTs take place in situ. In this process, liquid ammonia and hydrazine hydrate are used as the complexing and reducing agents, ${ }^{30}$ and Pd may be used as a mediator for interaction between MWCNTs and $\mathrm{Cu}$ nanoparticles. ${ }^{31}$ The transmission electron microscopy results indicated a uniform distribution of $\mathrm{Cu}$ nanoparticles $(2-5 \mathrm{~nm})$ on the CNTs (diameters between 20 and $60 \mathrm{~nm}$ ). The selected area electron diffraction (SAED) pattern confirms the presence of $\mathrm{Cu}$ particles with 111, 200 and 220 crystal planes. The $\mathrm{Cu}$ nanoparticle decorated Pd doped MWCNT buckypaper, having different $\mathrm{Cu}$ nanoparticle loadings, is found to possess a very low density ( $\sim 0.25$ to $0.40 \mathrm{~g}$ $\mathrm{cm}^{-3}$ ). The synthesized buckypaper having a thickness of 200 $\mu \mathrm{m}$ at $15 \% \mathrm{Cu}$ loading are found to exhibit an EMI SE of $\sim 35 \mathrm{~dB}$ (specific EMI SE $\sim 108 \mathrm{~dB} \mathrm{~cm}^{3} \mathrm{~g}^{-1}$ ), which, coupled with their good flexibility ${ }^{32}$ and lightweight could make them excellent candidates for large-scale EMI shielding applications.

\section{Experimental}

\subsection{Material synthesis technique}

MWCNTs, used in the present study, were procured from Nonosil and palladium chloride (99.99\%), copper sulphate $\left(\mathrm{CuSO}_{4} \cdot 5 \mathrm{H}_{2} \mathrm{O}\right)$ (99\%), liquid ammonia, and hydrazine hydrate were procured from Merck, India. Initially, the purified MWCNTs $(1 \mathrm{~g})$ are taken in $100 \mathrm{~mL}$ of ethyl alcohol and sonicated for $\sim 15$ minutes to obtain dispersed MWCNTs. An acidic solution ( $5 \mathrm{~mL} \mathrm{HCl}$ mixed in $500 \mathrm{~mL}$ of de-ionized (DI) water) having palladium chloride $\left(\mathrm{PdCl}_{2}, 0.02 \mathrm{~g} \mathrm{~L}^{-1}\right)$ and a small amount of $\mathrm{SnCl}_{2}\left(0.001 \mathrm{~g} \mathrm{~L}^{-1}\right)$ was then added to these dispersed MWCNTs for Pd doping. The mixture was then sonicated continuously for another 30 minutes and finally filtered. A brief description of the activation reaction has been discussed in the ESI (eqn I and II $\dagger$ ). The filtrate was dried at 300 ${ }^{\circ} \mathrm{C}$ with a heating rate of $100{ }^{\circ} \mathrm{C} \mathrm{min}^{-1}$, which results in $\mathrm{Pd}$ doped MWCNTs, denoted as PdCNTs in the subsequent discussions. The PdCNT powder was coated with $\mathrm{Cu}$ nanocrystalline particles with different $\mathrm{Cu}$ loadings (5, 15 and $25 \mathrm{wt} \%$ ) by an electroless technique. ${ }^{31}$ First, for the coating of $\mathrm{Cu}$ nanoparticles, bath solutions having $1 \mathrm{~L}$ of DI water and containing an appropriate amount of $\mathrm{Cu}$ ions, derived from the reduction of cupric sulphate $\left(\mathrm{CuSO}_{4} \cdot 5 \mathrm{H}_{2} \mathrm{O}\right)$ for various $\mathrm{Cu}$ loading concentrations (5, 15 and $25 \mathrm{wt} \%$ ), were separately prepared. In the bath solution, liquid ammonia was used as a complexing agent and the bath solutions were subjected to constant stirring throughout the experiment. In order to obtain uniform coating, the $\mathrm{pH}$ and temperature of bath solutions were maintained within $8-9$ and $40-50{ }^{\circ} \mathrm{C}$, respectively, using liquid ammonia solution. At the optimized temperature and $\mathrm{pH}$, hydrazine hydrate $(10 \mathrm{~mL})$ was added as a reducing agent to form $\mathrm{Cu}$ nanoparticles. This reaction was continued for $\sim 1 \mathrm{~h}$ to form $\mathrm{Cu}$ nanoparticle decorated PdCNT nanocomposites with varying $\mathrm{Cu}$ loadings on PdCNTs (as shown in Fig. 1). These nanocomposites will be denoted as $\mathrm{Cu}_{x} \mathrm{PdCNTs}$, where $x=0,5$,

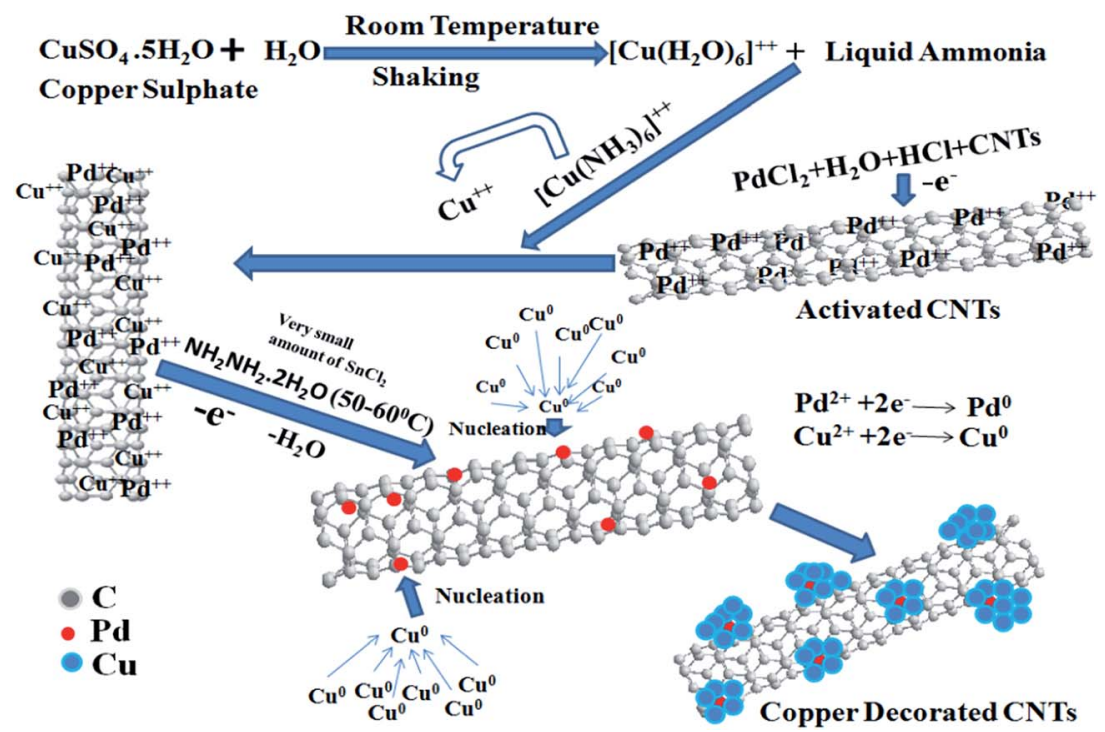

Fig. 1 Schematic of the synthesis mechanism for the decoration of Cu particles on PdCNTs. 
15 and 25 represent the wt\% loading of $\mathrm{Cu}$ nanoparticles on PdCNTs. The PdCNTs and nanocomposite network sheets (buckypaper) were fabricated using a vacuum filtration method $^{33}$ for electrical and EMI shielding measurements. A filter paper (Whatman no. 44) was used for filtration and porous metal sheets were used for the preparation of buckypaper of CNTs under rotary vacuum. The dispersed decorated CNTs were slowly poured onto the flat wet filter paper and after filtration they were allowed to dry. Finally, the buckypaper was dried for several hours at $80{ }^{\circ} \mathrm{C}$. This oven dried buckypaper was sintered at $500{ }^{\circ} \mathrm{C}$ in a nitrogen atmosphere.

\subsection{Material characterisation techniques}

Field emission scanning electron microscopy (FESEM) (ZEISSEVO MA10) and transmission electron microscopy (TEM) (FEI Tecnai T30) were used to study the morphology and microstructural characteristics of the synthesized sample. The physical and chemical nature of the composite was analyzed using a Raman spectroscope (Renishaw inVia, Macro Raman) having a $514.5 \mathrm{~nm}$ laser for excitation. The electrical conductivity was determined using a Keithley programmable current source (Model-6221) and a nano-voltmeter (Model-2182A). The buckypaper cut in rectangular sheets $\left(13 \times 7 \times 0.2 \mathrm{~mm}^{3}\right)$ and having four ohmic contacts on each end, made using silver paste, has been used for electrical measurements. The phase identification and crystallite size estimation were carried out using X-ray powder diffraction (XRD) (Rigaku, MiniFlexII). To explore the EMI-SE and dielectric measurements of the nanocomposites, a Vector Network analyzer (model-E8362B) was employed on rectangular shaped $\left(15.8 \times 7.9 \times 0.2 \mathrm{~mm}^{3}\right)$ buckypaper inserted in a $\mathrm{Cu}$ sample holder connected between the wave-guide flanges of the network analyzer for operation in the Ku-band $(12.4-18.0 \mathrm{GHz})$.

\section{Results and discussion}

The XRD pattern of the $\mathrm{Cu}_{25}$ PdCNT nanocomposite is shown in Fig. 2(A). The peak observed at $2 \theta=26.1^{\circ}$ corresponds to the hexagonal (002) plane of MWCNTs and the smaller peaks at $2 \theta$ $=43.8^{\circ}$ and $53.4^{\circ}$ represent (111) and (200) fcc planes of $\mathrm{Cu},{ }^{34}$ as indicated by the enlarged image of the XRD pattern (inset of
Fig. 2(A)), which was also confirmed by SAED patterns. The Raman spectra (Fig. 2(B)) of MWCNT, $\mathrm{Cu}_{0} \mathrm{PdCNT}$ and $\mathrm{Cu}_{25^{-}}$ PdCNT nanocomposites show two clear bands at $1577 \mathrm{~cm}^{-1}$ (G band) and $1359 \mathrm{~cm}^{-1}$ (D band), which confirm the presence of carbon. ${ }^{35}$ The Raman spectra also indicate the disorder induced (D-band) and graphitized carbon (G-band) 2D bands that appear at $2709 \mathrm{~cm}^{-1}$. Here, we have observed a change in the intensity ratio of $I_{\mathrm{G}} / I_{\mathrm{D}}$, which may be due to metal doping in the MWCNT structure as unlocalized free electrons from $\mathrm{Cu}$ create an effective change in $\mathrm{E}_{2 \mathrm{~g}}$ photon corresponding to $\mathrm{sp}^{2}$ atoms $(\mathrm{G}$ band). ${ }^{36}$

The microstructure of $\mathrm{Cu}$ particle decorated PdCNTs $(\mathrm{Cu}=$ 5, 15 and 25 wt\% loading) is shown in Fig. 3(A-D). Fig. 3(A) depicts a decoration of $\mathrm{Cu}$ nanoparticles on PdCNTs with $5 \%$ $\mathrm{Cu}$ loading and suggests that the diameter of MWCNTs is $\sim 20-$ $60 \mathrm{~nm}$. Fig 3(B) shows the image of the $15 \mathrm{wt} \% \mathrm{Cu}$ loaded nanocomposite, which suggests a reasonably uniform distribution of $\mathrm{Cu}$ nanoparticles in the nanocomposite. However, on further increasing the $\mathrm{Cu} \mathrm{wt} \%$ in the nanocomposite $(>15 \%)$, the agglomeration is clearly evident as shown in Fig. 3(D). Elemental analysis of the nanocomposite is shown in the inset of Fig. 3(D), which confirmed the presence of carbon and $\mathrm{Cu}$ in the nanocomposite. Palladium has been confirmed in PdCNTs by the elemental analysis to be very small in quantity and the corresponding details are given in Fig. $1 \mathrm{~S}(\mathrm{~A}-\mathrm{C}) . \dagger$ However, $\mathrm{Pd}$ is not detected in the case of the $\mathrm{Cu}_{x} \mathrm{PdCNT}$ nanocomposite, which is due to the small quantity ( $0.005 \mathrm{~g}$ in the $1 \mathrm{~g}$ CNTs) of Pd used during the synthesis. The corresponding quantitative elemental analysis and elemental distribution mapping on $\mathrm{Cu}_{15} \mathrm{PdCNTs}$ are shown in the ESI (Fig. $2 \mathrm{~S}(\mathrm{~A}-\mathrm{C}) \dagger$ ). Thermogravimetric analysis of the $\mathrm{Cu}_{15}$ PdCNT nanocomposite also was conducted in air and inert atmospheres for the confirmation of wt $\% \mathrm{Cu}$ present and this result confirmed that $\sim 15 \% \mathrm{Cu}$ was present in the nanocomposite, Fig. $2 \mathrm{~S}(\mathrm{D}) . \dagger$ The microstructure of $\mathrm{Cu}_{15} \mathrm{PdCNT}$ buckypaper exhibits a uniform decoration of $\mathrm{Cu}$ nanoparticles on PdCNTs, which are entangled with each other and for detail description see Fig. 3S (as ESI $\dagger$ ).

Transmission electron microscopy (TEM) experiments were conducted on the $\mathrm{Cu}_{x}$ PdCNTs samples to show the decoration of $\mathrm{Cu}$ nanoparticles in CNTs. It was noted that the $\mathrm{Cu}$ nanoparticles of 2 to $5 \mathrm{~nm}$ in size (marked with arrows) were distributed on a CNT of a diameter of about $35 \mathrm{~nm}$ in
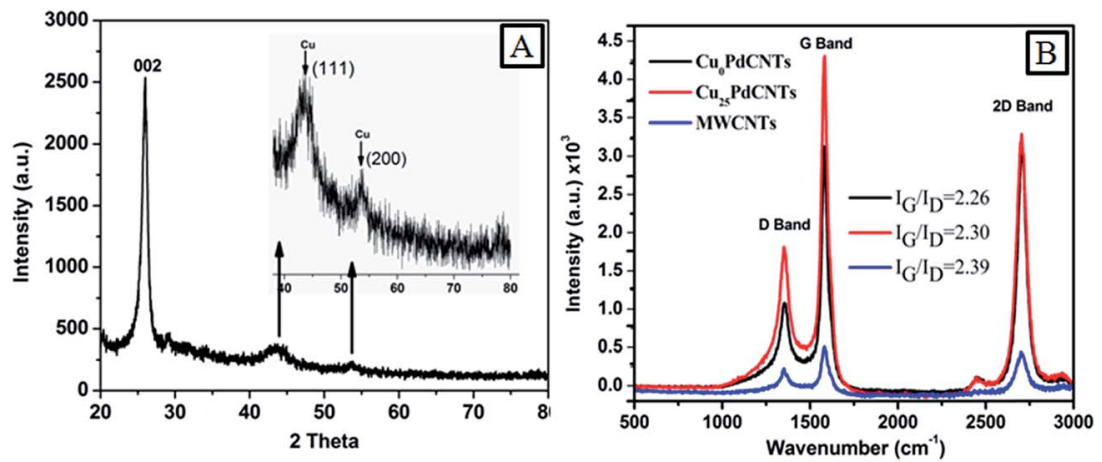

Fig. 2 (A) XRD pattern of the $\mathrm{Cu}_{25} \mathrm{PdCNT}$ nanocomposite; (B) comparative Raman spectra of $\mathrm{Cu}_{0} \mathrm{PdCNTs}$ and $\mathrm{Cu}_{25}$ PdCNTs nanocomposites. 


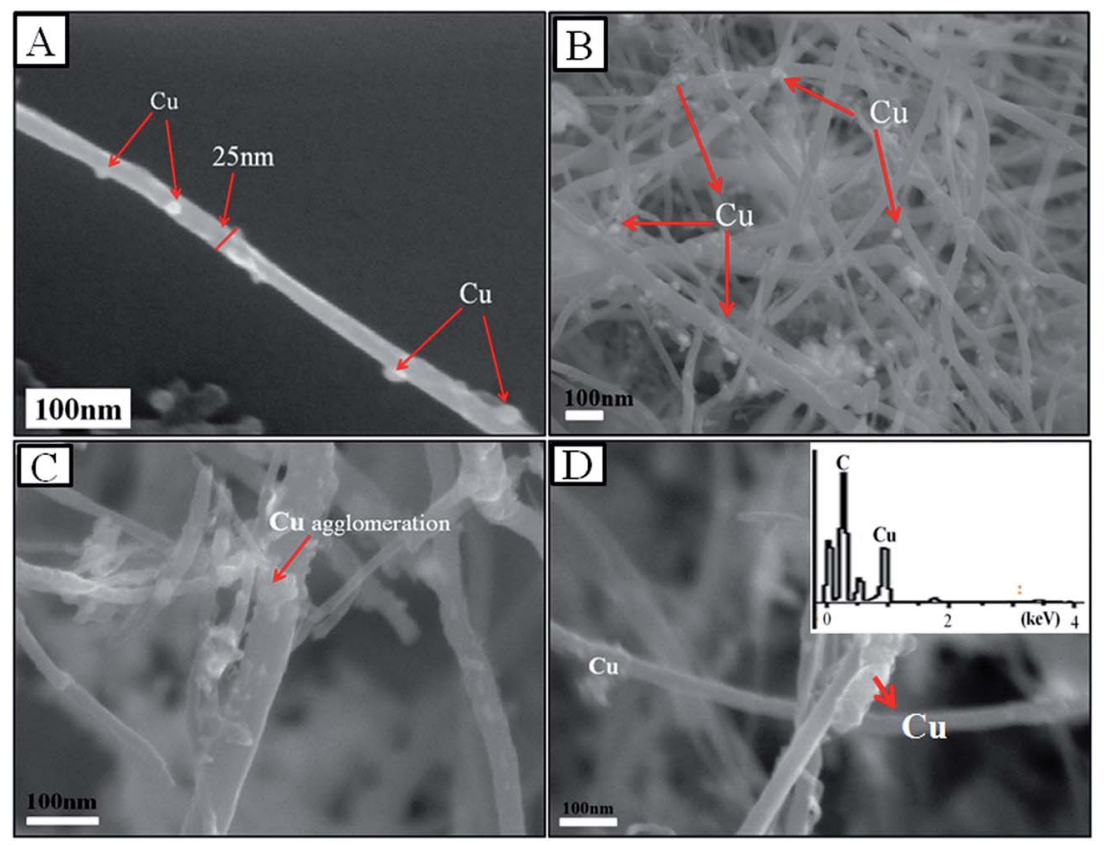

Fig. 3 FESEM image of $\mathrm{Cu}_{x} \mathrm{PdCNT}$ nanocomposites (A) $\mathrm{Cu}_{5} \mathrm{PdCNT}$ nanocomposite; (B) $\mathrm{Cu}_{15} \mathrm{PdCNT}$ buckypaper; (C) and (D) Cu 25 PdCNT nanocomposite; the inset in (D) shows the EDX analysis of the $\mathrm{Cu}_{25} \mathrm{PdCNTS}$.

$\mathrm{Cu}_{5}$ PdCNTs (Fig. $4 \mathrm{~S}(\mathrm{~A}) \dagger$ ). The low resolution TEM image of $\mathrm{Cu}_{15}$ PdCNTs (Fig. 4(A)) displayed a dense-distribution of multiwalled carbon nanotubes (MWCNTs) in general. However, the magnified image revealed a uniform distribution of $\mathrm{Cu}$ NPs (marked with a set of arrows) on MWCNTs (Fig. 4(B)). It was interesting to note that the presence of $\mathrm{Cu}$ was either on the outer surfaces of the carbon nanotubes or trapped in the multiwalled structures of individual nanotubes. The inset in Fig. 4(B) shows a $\mathrm{Cu}$ nanoparticle present in the core region of an individual carbon nanotube with a diameter of about $15 \mathrm{~nm}$ and length covering approximately $40 \mathrm{~nm}$. Fig. 4(C) shows an ultrafine $\mathrm{Cu}$ nanoparticle mostly on the surface of a nanotube of about $40 \mathrm{~nm}$ in outer diameter of the tube. Atomic scale imaging results show that the interlayer separation of the multiwall is approximately $0.34 \mathrm{~nm}$ (inset in Fig. 4(C)). Although, in general, the interlayer separation of the walls is quite parallel, the regions around the nanoparticle (approximately $10 \mathrm{~nm}$ ) are disturbed with the wavy geometry of interlayers of nanotubes (Fig. 4(D)). It is noted explicitly that the $\mathrm{Cu}$ nanoparticles are intact and very cohesive with the surfaces of the nanotube. The gray level contrast and high resolution images were obvious to distinguish the carbon nanotubes associated with $\mathrm{Cu}$ nanoparticles in the composite microstructure. However, further revelation $(4 \mathrm{~S}(\mathrm{~B}) \dagger)$ was possible by recording the atomic scale image of $\mathrm{Cu}$ and subsequent identification of the $0.21 \mathrm{~nm}$ interplanar spacing of $\mathrm{Cu}$, along 111 planes (crystal structure: fcc, lattice, ref: JCPDS copper file no. 04-0836). Moreover, a corresponding fast Fourier transform (FFT) of the composite micrograph delineates the presence of $0.34 \mathrm{~nm}$ and $0.21 \mathrm{~nm}$ spacing that evolved from MWCNTs and $\mathrm{Cu}$, respectively, in the reciprocal space (inset in $4 \mathrm{~S}(\mathrm{~B}) \dagger)$. A micrograph of the $\mathrm{Cu}_{25} \mathrm{PdCNT}$ nanocomposite is shown in
Fig. $4 \mathrm{~S}(\mathrm{C}), \dagger$ which clearly exhibits the agglomeration of $\mathrm{Cu}$ nanoparticles on further increasing the $\mathrm{Cu} \%$ loading.

The room temperature DC electrical conductivity of $\mathrm{Cu}_{x} \mathrm{PdCNT}$ nanocomposites, investigated by a standard four-

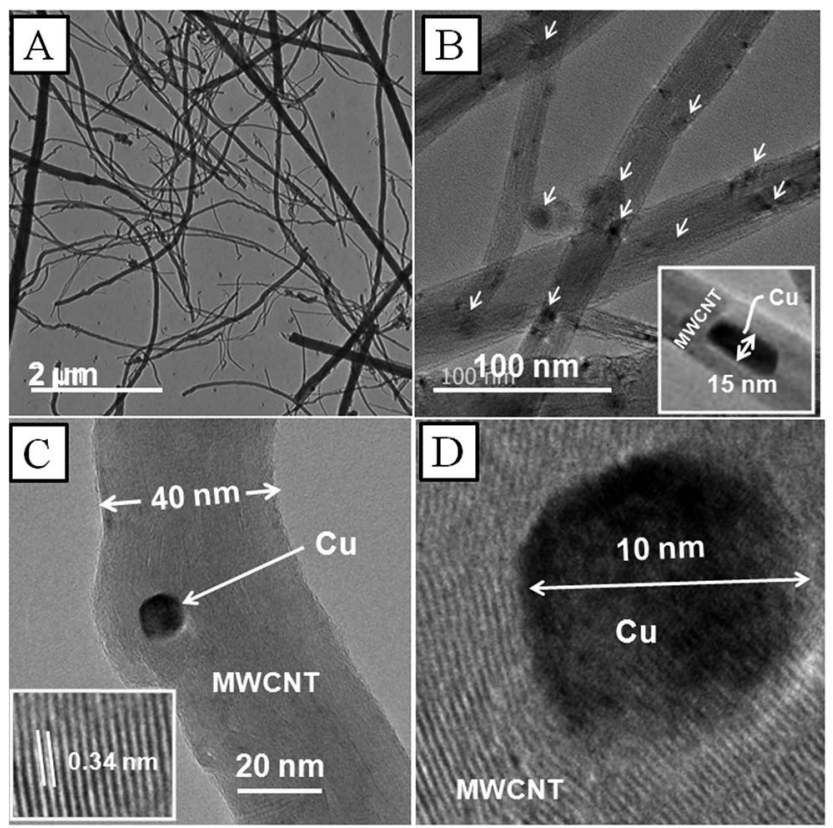

Fig. 4 TEM micrographs of $\mathrm{Cu}_{15} \mathrm{PdCNTS}$ showing the composite microstructure of MWCNTs and Cu NPs: (A) large area distribution of MWCNTs and $\mathrm{Cu}$, (B) high magnification micrograph of nanotubes with nanoparticles, (C) single nanoparticle on the outer surface of a CNT, and (D) cohesive microstructure of the multiwall of a CNT with a nanoparticle. Insets: nanoparticle inside the CNT (B), resolution of the multiwall (C). 
probe technique, is shown in Fig. 5. Since both $\mathrm{Cu}$ and MWCNTs possess very good electrical conductivity, ${ }^{26}$ the resultant electrical conductivity of $\mathrm{Cu}_{x} \mathrm{PdCNT}$ nanocomposites escalates sharply with increasing $\mathrm{wt} \%$ loading of $\mathrm{Cu}$ i.e. from $3.64 \mathrm{~S} \mathrm{~cm}^{-1}$ (Cu${ }_{0}$ PdCNTs) to $11.64 \mathrm{~S} \mathrm{~cm}^{-1}$ ( $\mathrm{Cu}_{15}$ PdCNTs). Interestingly, Fig. 5 suggests that further increasing the loading of $\mathrm{Cu}$ nanoparticles to $25 \mathrm{wt} \%$ shows an adverse effect on the electrical conductivity and it decreases to $8.95 \mathrm{~S} \mathrm{~cm}^{-1}$, which suggests that the optimum threshold loading limit of $\mathrm{Cu}$ nanoparticles is around $15 \mathrm{wt} \%$. This may be due to the agglomeration of $\mathrm{Cu}$ nanoparticles with $\mathrm{Cu}$ loading $>15 \mathrm{wt} \%$, which is in agreement with the TEM results on the $\mathrm{Cu}_{25} \mathrm{PdCNT}$ nanocomposite (Fig. 4(D)). A similar phenomenon has also been reported earlier in Ag nanoparticle decorated CNTs, which may lead to a decrease in the conductivity and other properties

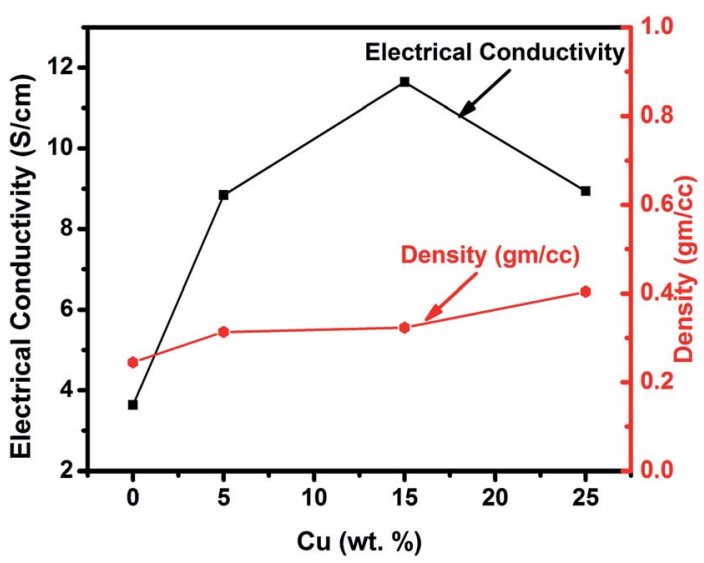

Fig. 5 Variation of DC electrical conductivity and density with Cu wt\% nanoparticle loading in $\mathrm{Cu}_{x} \mathrm{PdCNT}$ nanocomposites (where $x=0,5,15$ and $25 \mathrm{wt} \%)$. of the nanocomposites. ${ }^{37}$ This suggests that a $\mathrm{Cu}$ loading $\leq 15$ $\mathrm{wt} \%$ results in a uniform distribution of $\mathrm{Cu}$ nanoparticles on PdCNTs, leading to an enhanced electrical conductivity in $\mathrm{Cu}$ nanoparticle decorated PdCNT nanocomposites. ${ }^{18}$ The density variation of the $\mathrm{Cu}_{x} \mathrm{PdCNT}$ nanocomposite as a function of $\mathrm{wt} \%$ of the $\mathrm{Cu}$ nanoparticle loading in PdCNTs is also shown in Fig. 5. This figure suggests that the density of the $\mathrm{Cu}_{x} \mathrm{PdCNT}$ nanocomposite continues to increase with increasing $\mathrm{Cu}$ nanoparticle loading and increases from $0.24 \mathrm{~g} \mathrm{~cm}^{-3}$ (unloaded) to $0.40 \mathrm{~g} \mathrm{~cm}^{-3}$ (25 wt\% Cu particle loading). This increase in the density of the $\mathrm{Cu}_{x} \mathrm{PdCNT}$ nanocomposite with higher $\mathrm{Cu}$ nanoparticle loading is attributed to the high density of $\mathrm{Cu}$ compared to MWCNTs.

The relative complex dielectric parameters have been estimated from experimental scattering parameters $\left(\begin{array}{lll}S_{11} & \& & S_{21}\end{array}\right)$ obtained by standard Nicolson-Ross and Weir theoretical calculations. ${ }^{38}$ The estimated dielectric constant $\left(\varepsilon^{\prime}\right)$ symbolizes the amount of polarization occurring in the material or the storage ability of the electrical energy, while the dielectric loss $\left(\varepsilon^{\prime \prime}\right)$ signifies the dissipated electrical energy. The frequency dependence of $\varepsilon^{\prime}$ and $\varepsilon^{\prime \prime}$ in the $\mathrm{Ku}$ band (12.4 to $18 \mathrm{GHz}$ ) for all the $\mathrm{Cu}_{x} \mathrm{PdCNT}$ nanocomposites and buckypaper is plotted in Fig. $7(\mathrm{a}$ and $\mathrm{b})$. The effective value of real and imaginary parts of permittivity, for the entire frequency range, was extracted by averaging over 201 data points. The overall averaged values of $\varepsilon^{\prime}$ are found to be $\sim 20.10,41.01,47.14$ and 19.56, while that of $\varepsilon^{\prime \prime}$ are $\sim 7.83,23.25,29.63$ and 10.88 for $0,5,15$ and $25 \mathrm{Cu} w t \%$, respectively. An increasing trend in these values was observed for a $\mathrm{Cu}$ nanoparticle loading up to $15 \mathrm{wt} \%$, which falls drastically on further increasing the $\mathrm{Cu}$ nanoparticle loading to $25 \%$, which is nearly to the conductivity pattern as shown in see Fig. 5, Hence, it can be concluded that increasing the wt $\%$ loading of $\mathrm{Cu}$ nanoparticles (upto 15\%) shows enhancement in the values of $\varepsilon^{\prime}$ and $\varepsilon^{\prime \prime}$, which may be due to the higher
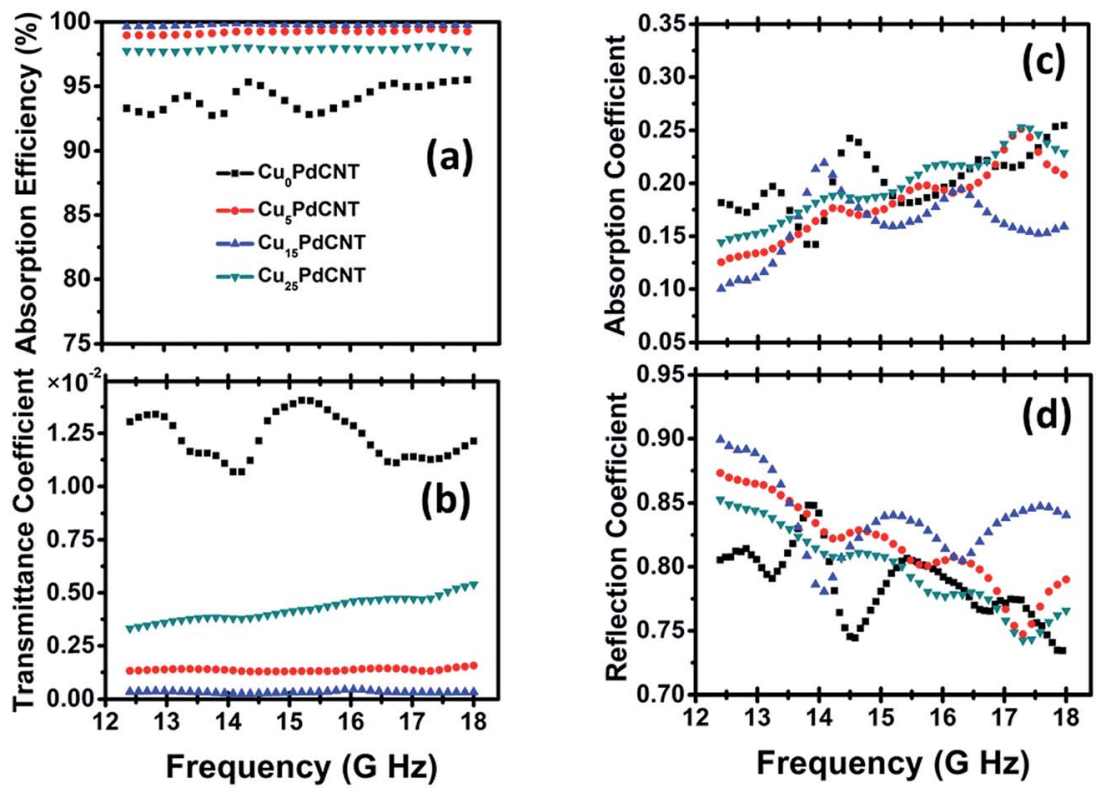

Fig. 6 EMI parameters of $\mathrm{Cu}_{x} \mathrm{PdCNT}$ nanocomposites, (a) absorption efficiency, (b) transmission coefficient, (c) absorption coefficient and (d) reflection coefficient. 

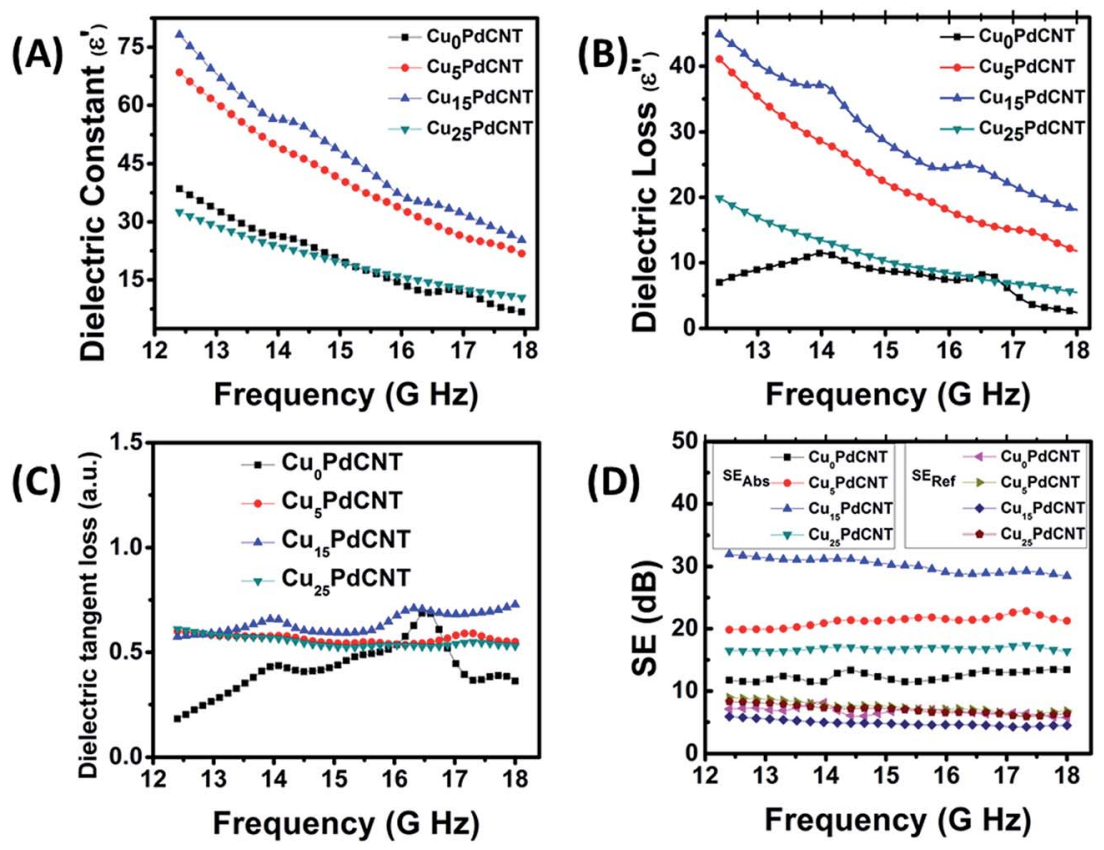

Fig. 7 Frequency dependence of complex permittivity of $\mathrm{Cu}_{x} \mathrm{PdCNT}$ nanocomposites (A) real part $\left(\varepsilon^{\prime}\right)$; (B) imaginary part $\left(\varepsilon^{\prime \prime}\right)$; $(C)$ dielectric tangent loss and (D) EMI SE due to absorption ( $\left.\mathrm{SE}_{\mathrm{Abs}}\right)$ and reflection ( $\left.\mathrm{SE}_{\mathrm{Ref}}\right)$.

conductivity of $\mathrm{Cu}_{x} \mathrm{PdCNT}$ nanocomposites compared to $\mathrm{Cu}_{25}$ PdCNTs. Further, the resulting relative complex permittivity, which is a measure of the polarizability of a material, induces dipolar and electric polarization in the presence of microwaves.

According to EM theory, dielectric losses are the result of complex phenomena like natural resonance, dipole relaxation and electronic polarization. In the present nanocomposites, $\mathrm{Pd}$ may act as a polarized centre on the surface of the MWCNTs. The high aspect ratio of MWCNTs decorated with $\mathrm{Cu}$ nanoparticles also enhances the absorption properties. The existence of interfaces between $\mathrm{Cu}$ nanoparticles and MWCNTs is also responsible for interfacial polarization, which further contributes to dielectric losses. Interfacial polarization occurs in heterogeneous media due to the accumulation of charges at the interfaces. The increase in the averaged values of $\varepsilon^{\prime \prime}$ with the higher $\mathrm{wt} \%$ loading of $\mathrm{Cu}$ nanoparticles $(\leq 15 \%)$ is attributed to the formation of a connecting network between PdCNTs and $\mathrm{Cu}$ nanoparticles in $\mathrm{Cu}_{x}$ PdCNT nanocomposites. In addition, the conducting nature of MWCNTs is further helpful in enhancing the dielectric loss. ${ }^{26}$ The natural resonances in the Ku-band can be attributed to the small size of $\mathrm{Cu}$ nanoparticles on the PdCNT matrix as the anisotropy energy of fine-size materials, especially in the nanoscale, ${ }^{21,25}$ is expected to be higher due to the surface anisotropic field, termed as the size effect, ${ }^{4,39}$ which contributes to the enhancement of the microwave absorption.

Furthermore, the reflection coefficient $(R)$, transmittance coefficient $(T)$, absorption coefficient $(A)$, and absorption efficiency of the nanocomposites were evaluated using $S$ parameters as, $R=\left|S_{11}\right|^{2}=\left|S_{22}\right|^{2}, T=\left|S_{21}\right|^{2}=\left|S_{12}\right|^{2}, A=1-R-T$ and
$A_{\text {eff }}=(1-R-\mathrm{T}) /(1-R)$, respectively. Fig. 6(a-d) show the calculated absorption efficiency, $T, A$ and $R$. The $T$ value of $\mathrm{Cu}_{x}$ PdCNTs is found to be minimum for $\mathrm{Cu}_{15}$ PdCNT (less than 0.1) i.e. more $\mathrm{EM}$ waves are consumed by the $\mathrm{Cu}_{15} \mathrm{PdCNT}$ nanocomposite, which leads to a more significant decrease of the $T$ values, as shown in Fig. 6(b). As shown in Fig. 6(c), the A values of the $\mathrm{Cu}_{x} \mathrm{PdCNT}$ nanocomposites were in the range of $0.1-0.25$. The $R$ values of the $\mathrm{Cu}_{x} \mathrm{PdCNT}$ nanocomposites were in the range of $0.75-0.90$. Moreover, the absorption efficiency (\%) of the $\mathrm{Cu}_{x} \mathrm{PdCNT}$ nanocomposites increases with increasing weight $\%$ of $\mathrm{Cu}$ (Fig. $6(\mathrm{a}))$ and $\mathrm{Cu}_{15}$ PdCNTs show a \% absorption efficiency more than $99.9 \%$.

When EM radiation is incident on a shield, some part of the incident wave is absorbed and some part is reflected from the surface and the rest is transmitted through the shield. Hence, the total EMI SE $\left(\mathrm{SE}_{\mathrm{Tot}}\right)$ is the sum of the contributions from absorption $\left(\mathrm{SE}_{\mathrm{Abs}}\right)$, reflection $\left(\mathrm{SE}_{\mathrm{Ref}}\right)$, and transmission or multiple reflections $\left(\mathrm{SE}_{\mathrm{MIt}}\right)$. Therefore the EMI SE of any material can be expressed as. ${ }^{40-45}$

$$
\begin{aligned}
\mathrm{SE}_{\mathrm{Tot}}(\mathrm{dB}) & =\mathrm{SE}_{\mathrm{Ref}}+\mathrm{SE}_{\mathrm{Abs}}+\mathrm{SE}_{\mathrm{Mlt}}=10 \log \left(P_{\mathrm{T}} / P_{\mathrm{I}}\right) \\
& =20 \log \left(E_{\mathrm{T}} / E_{\mathrm{I}}\right)
\end{aligned}
$$

where, $P_{\mathrm{I}}\left(E_{\mathrm{I}}\right)$ and $P_{\mathrm{T}}\left(E_{\mathrm{T}}\right)$ are the incident and transmitted power (electric field intensity) of EM waves, respectively. The correction term $\mathrm{SE}_{\mathrm{Mlt}}$ can be ignored for practical applications when $\mathrm{SE}_{\mathrm{Tot}}>10 \mathrm{~dB} .{ }^{46,47}$ Hence, the equation (eqn (1)) reduces to:

$$
\mathrm{SE}_{\mathrm{Tot}}(\mathrm{dB}) \approx \mathrm{SE}_{\mathrm{Ref}}+\mathrm{SE}_{\mathrm{Abs}}
$$

Furthermore, $\mathrm{SE}_{\mathrm{A}}$ and $\mathrm{SE}_{\mathrm{R}}$ are obtained by using following equations: 


$$
\begin{aligned}
\mathrm{SE}_{\mathrm{Abs}}(\mathrm{dB}) & =20\{t / \delta\} \log e=20 d \sqrt{\mu \omega \sigma_{\mathrm{ac}} / 2} \log e=8.68\{t / \delta\} \\
& =8.68 t \sqrt{\sigma \omega \mu^{\prime} / 2}
\end{aligned}
$$

$$
\mathrm{SE}_{\mathrm{Ref}}(\mathrm{dB})=10 \log \left\{\sigma_{\mathrm{ac}} / 16 \omega \varepsilon_{0} \mu^{\prime}\right\}
$$

The $\sigma_{\mathrm{ac}}$ and $\delta$ can be related to the imaginary permittivity $\left(\varepsilon^{\prime \prime}\right)$ and real permeability $\left(\mu^{\prime}\right)$ as $\sigma_{\mathrm{ac}}=\omega \varepsilon_{0} \varepsilon^{\prime \prime}$ and $\delta=\sqrt{2 / \sigma \omega \mu^{\prime}}$, respectively.

The above equations suggest that electrical conductivity and complex permittivity are two governing parameters for the suppression of reflection or improvement in microwave absorption. Therefore, the decoration of $\mathrm{Cu}$ nanoparticles (more conducting) in PdCNTs (lesser conducting) in an appropriate amount is expected to improve the absorption of EM waves. The variations of $\mathrm{SE}_{\mathrm{Abs}}$ and $\mathrm{SE}_{\mathrm{Ref}}$ over the frequency range of 12.4-18 GHz are shown in Fig. 7(D), from which it can be concluded that the $\mathrm{SE}$ due to $\mathrm{SE}_{\mathrm{Abs}}$ for $\mathrm{Cu}_{x} \mathrm{PdCNT}$ nanocomposites, when averaged over the entire frequency range, has been found to vary from 12.36 to $30.16 \mathrm{~dB}$ but $\mathrm{SE}_{\mathrm{Ref}}$ has very less variation of $6.5 \pm 1.7 \mathrm{~dB}$. Furthermore, the sample $\mathrm{Cu}_{15}$ PdCNTs show a maximum $\mathrm{SE}_{\mathrm{Tot}}$ of $34.98 \mathrm{~dB}$ which is conquered by $\mathrm{SE}_{\mathrm{Abs}}$ (30.15 dB) and partially shared by $\mathrm{SE}_{\mathrm{Ref}}(4.82 \mathrm{~dB})$. The $\mathrm{SE}_{\mathrm{Tot}}$ achieved for the $\mathrm{Cu}$ decorated nanocomposites is significantly higher than that of the $\mathrm{Cu}_{0}$ PdCNTs, which shows that $\mathrm{Cu}$ decoration plays a crucial role in the effective enhancement of $\mathrm{SE}$. The $\mathrm{SE}_{\mathrm{Abs}}$ becomes more dominant as compared to the $\mathrm{SE}_{\mathrm{Ref}}$ in the microwave range. ${ }^{44}$ From the detailed shielding analysis, it has been observed that the $\mathrm{SE}_{\mathrm{Tot}}$ value increases with an increase in the $\mathrm{Cu}$ content and when the $\mathrm{Cu}$ content reaches $15 \mathrm{wt} \%$ in PdCNTs, the observed $\mathrm{SE}_{\mathrm{Ref}}$ value $<5 \mathrm{~dB}$, which is the minimum value of reflection achieved while retaining optimum microwave absorption. Further the loading of $\mathrm{Cu}$ crosses the threshold limit (as observed in the conducting behaviour) and $\mathrm{SE}_{\mathrm{Tot}}$ decreases, suggesting that $\mathrm{Cu}_{15}$ PdCNTs are found to have an optimum composition. However, the EMI SE of pristine MWCNTs is shown in the ESI (Fig. 5(S) $\dagger$ ).

The dielectric tangent loss $\left(\tan \delta \varepsilon=\varepsilon^{\prime \prime} / \varepsilon^{\prime}\right)$ of $\mathrm{Cu}_{x} \mathrm{PdCNT}$ nanocomposites is shown in Fig. 7(C). The observed tan $\delta$ values for all the nanocomposites were $\geq 0.2$ in the entire frequency range, which is caused by the good conductivity of $\mathrm{Cu}$ and $\mathrm{Pd}$ nanoparticles and their associated polarization and relaxation. Two hoops are observed for these nanocomposites as revealed in Fig. 7(C), which suggest the excellent microwave shielding performance of $\mathrm{Cu}_{x}$ PdCNT nanocomposites, which mainly may be attributed to two factors: impedance matching and EM wave attenuation.

The EMI shielding using highly conducting materials, such as metals, is known to be governed by reflection rather than absorption. On the other hand, hybrid conducting nanocomposites provide EMI shielding predominantly due to absorption owing to the presence of electric dipoles. ${ }^{41,48} \mathrm{We}$ observed a similar phenomenon for our nanocomposites, wherein the total EMI SE achieved is greater than the recommended limit of SE $(20 \mathrm{~dB})$ for commercial applications. ${ }^{49}$
Therefore, the as-fabricated $\mathrm{Cu}$ decorated buckypaper ( $\mathrm{Cu}_{15}$ PdCNTs) could be a potential choice for futuristic EMI shielding materials. Interestingly, the desired value of EMI SE can be achieved by scaling the loading level of $\mathrm{Cu}$ nanoparticles depending on the specific requirement in the desired application. Our $\mathrm{Cu}_{15} \mathrm{PdCNT}$ nanocomposites exhibited improved microwave absorption properties in comparison to pristine PdCNTs, MWCNTs, and PANI/MWCNT nanocomposites reported earlier..$^{50,51}$

\section{Conclusions}

We have demonstrated the synthesis of a lightweight and flexible $\mathrm{Cu}$ nanoparticle decorated PdCNT buckypaper with high EMI shielding effectiveness, using a simple and cost-effective electroless technique. These nanocomposites have been characterized by employing XRD, FESEM, HRTEM, and Raman spectroscopy, which suggest a uniform selective decoration of $\mathrm{Cu}$ nanoparticles on PdCNTs up to a loading limit of $\sim 15 \mathrm{wt} \%$, beyond which the $\mathrm{Cu}$ nanoparticles tend to agglomerate. The EMI shielding effectiveness of $35 \mathrm{~dB}(\sim 99.99 \%)$ and a high specific EMI SE of $\sim 108 \mathrm{~dB} \mathrm{~cm}^{3} \mathrm{~g}^{-1}$ have been realized in the $\mathrm{Ku}$-band for $\mathrm{Cu}_{x}$ PdCNT buckypaper (thickness of $200 \mu \mathrm{m}$ ) at $15 \mathrm{wt} \%$ loading of $\mathrm{Cu}$ nanoparticles. It is suggested that the $\mathrm{Cu}$ nanoparticle decorated Pd doped MWCNTs could find promising EMI shielding applications in the $\mathrm{Ku}$ band, wherein the EMI SE can be tuned depending on the application by tailoring the $\mathrm{Cu}$ nanoparticle loading on MWCNTs.

\section{Acknowledgements}

The authors are thankful to Mr Naval, Mr Jay Tavale, Dr Sakshi and Ms Kriti for their valuable help in X-ray diffraction and SEM/TEM studies, respectively. One of the authors (Mr Anil Kumar) is thankful to MNRE, India for the financial assistance.

\section{References}

1 S. Yang, K. Lozano, A. Lomeli, H. D. Foltz and R. Jones, Compos. Appl. Sci. Manuf., 2005, 36, 691-697.

2 N. Li, Y. Huang, F. Du, X. He, X. Lin, H. Gao, Y. Ma, F. Li, Y. Chen and P. C. Eklund, Nano Lett., 2006, 6, 1141-1145.

3 M. H. Al-Saleh and U. Sundararaj, Carbon, 2009, 47, 17381746.

4 A. P. Singh, M. Mishra, P. Sambyal, B. K. Gupta, B. P. Singh, A. Chandra and S. K. Dhawan, J. Mater. Chem. A, 2014, 2, 3581-3593.

5 J. Wang, C. Xiang, Q. Liu, Y. Pan and J. Guo, Adv. Funct. Mater., 2008, 18, 2995-3002.

6 Y. Yang, M. C. Gupta, K. L. Dudley and R. W. Lawrence, Nano Lett., 2005, 5, 2131-2134.

7 A. Celzard, E. McRae, G. Furdin and J. F. Marêché, J. Phys.: Condens. Matter, 1997, 9, 2225.

8 S. H. Park, P. Theilmann, K. Yang, A. M. Rao and P. R. Bandaru, Appl. Phys. Lett., 2010, 96, 043115.

9 S. Palaniappan and B. H. Narayana, J. Polym. Sci., Part A: Polym. Chem., 1994, 32, 2431-2436. 
10 T. K. Gupta, B. P. Singh, S. R. Dhakate, V. N. Singh and R. B. Mathur, J. Mater. Chem. A, 2013, 1, 9138-9149.

11 K. Singh, A. Ohlan, V. H. Pham, Balasubramaniyan R., S. Varshney, J. Jang, S. H. Hur, W. M. Choi, M. Kumar, S. K. Dhawan, B.-S. Kong and J. S. Chung, Nanoscale, 2013, 5, 2411-2420.

12 R. Kumar, S. R. Dhakate, T. Gupta, P. Saini, B. P. Singh and R. B. Mathur, J. Mater. Chem. A, 2013, 1, 5727-5735.

13 Q. Liu, J. Gu, W. Zhang, Y. Miyamoto, Z. Chen and D. Zhang, J. Mater. Chem., 2012, 22, 21183-21188.

14 M. H. Al-Saleh, W. H. Saadeh and U. Sundararaj, Carbon, 2013, 60, 146-156.

15 Y. Chen, Y. Li, M. Yip and N. Tai, Compos. Sci. Technol., 2013, 80, 80-86.

16 S.-S. Tzeng and F.-Y. Chang, Mater. Sci. Eng., A, 2001, 302, 258-267.

17 A. A. Al-Ghamdi and F. El-Tantawy, Compos. Appl. Sci. Manuf., 2010, 41, 1693-1701.

18 J. Zhaoa and R.-H. Xieb, J. Nanosci. Nanotechnol., 2003, 3, 459-478.

19 A. Kumar, M. Kaur, R. Kumar, P. Sengupta, V. Raman, G. Bhatia and K. Sood, J. Mater. Sci., 2010, 45, 1393-1400.

20 A. Kumar, A. P. Singh, S. Kumari, P. K. Dutta, S. K. Dhawan and A. Dhar, J. Mater. Chem. A, 2014, 2, 16632-16639.

21 J. M. Planeix, N. Coustel, B. Coq, V. Brotons, P. S. Kumbhar, R. Dutartre, P. Geneste, P. Bernier and P. M. Ajayan, J. Am. Chem. Soc., 1994, 116, 7935-7936.

22 F. Wang, S. Arai and M. Endo, Electrochem. Commun., 2004, 6, 1042-1044.

23 A. V. Ellis, K. Vijayamohanan, R. Goswami, N. Chakrapani, L. S. Ramanathan, P. M. Ajayan and G. Ramanath, Nano Lett., 2003, 3, 279-282.

24 B. M. Quinn, C. Dekker and S. G. Lemay, J. Am. Chem. Soc., 2005, 127, 6146-6147.

25 Y. Zhang, N. W. Franklin, R. J. Chen and H. Dai, Chem. Phys. Lett., 2000, 331, 35-41.

26 A. P. Singh, B. K. Gupta, M. Mishra, Govind, A. Chandra, R. B. Mathur and S. K. Dhawan, Carbon, 2013, 56, 86-96.

27 H. M. Kim, K. Kim, C. Y. Lee, J. Joo, S. J. Cho, H. S. Yoon, D. A. Pejaković, J. W. Yoo and A. J. Epstein, Appl. Phys. Lett., 2004, 84, 589-591.

28 B.-W. Li, Y. Shen, Z.-X. Yue and C.-W. Nan, Appl. Phys. Lett., 2006, 89, 132504.

29 W. Zhao, M. Li, Z. Zhang and H.-X. Peng, Int. J. Smart Nano Mater., 2010, 1, 249-260.

30 P.-G. Ren, D.-X. Yan, X. Ji, T. Chen and Z.-M. Li, Nanotechnology, 2011, 22, 055705.
31 R. Sharma, R. C. Agarwala and V. Agarwala, Appl. Surf. Sci., 2006, 252, 8487-8493.

32 M. Endo, H. Muramatsu, T. Hayashi, Y. A. Kim, M. Terrones and M. S. Dresselhaus, Nature, 2005, 433, 476.

33 Z. Wu, Z. Chen, X. Du, J. M. Logan, J. Sippel, M. Nikolou, K. Kamaras, J. R. Reynolds, D. B. Tanner, A. F. Hebard and A. G. Rinzler, Science, 2004, 305, 1273-1276.

34 N. Jha and S. Ramaprabhu, J. Phys. Chem. C, 2008, 112, 93159319.

35 H.-C. Kuan, C.-C. M. Ma, W.-P. Chang, S.-M. Yuen, H.-H. Wu and T.-M. Lee, Compos. Sci. Technol., 2005, 65, 1703-1710.

36 R. Zacharia, K. Y. Kim, A. K. M. Fazle Kibria and K. S. Nahm, Chem. Phys. Lett., 2005, 412, 369-375.

37 P. C. Ma, B. Z. Tang and J.-K. Kim, Carbon, 2008, 46, 1497-1505.

38 A. M. Nicolson and G. F. Ross, IEEE Trans. Instrum. Meas., 1970, 19, 377-382.

39 Y.-J. Chen, P. Gao, R.-X. Wang, C.-L. Zhu, L.-J. Wang, M.-S. Cao and H.-B. Jin, J. Phys. Chem. C, 2009, 113, 1006110064.

40 A. P. Singh, M. Mishra, A. Chandra and S. K. Dhawan, Nanotechnology, 2011, 22, 9.

41 A. P. Singh, P. Garg, F. Alam, K. Singh, R. B. Mathur, R. P. Tandon, A. Chandra and S. K. Dhawan, Carbon, 2012, 50, 3868-3875.

42 K. Singh, A. Ohlan, P. Saini and S. K. Dhawan, Polym. Adv. Technol., 2008, 19, 229-236.

43 V. K. Sachdev, K. Patel, S. Bhattacharya and R. P. Tandon, J. Appl. Polym. Sci., 2011, 120, 1100-1105.

44 A. P. Singh, M. Mishra, P. Sambyal, B. K. Gupta, B. P. Singh, A. Chandra and S. K. Dhawan, J. Mater. Chem. A, 2014, 2, 3581-3593.

45 M. Ashokkumar, N. T. Narayanan, B. K. Gupta, A. L. M. Reddy, A. P. Singh, S. K. Dhawan, B. Chandrasekaran, D. Rawat, S. Talapatra, P. M. Ajayan and P. Thanikaivelan, ACS Sustainable Chem. Eng., 2013, 1, 619-626.

46 N. C. Das, D. Das, T. K. Khastgir and A. C. Chakrraborthy, Compos. Appl. Sci. Manuf., 2000, 31, 1069-1081.

47 N. F. Colaneri and L. W. Shacklette, IEEE Trans. Instrum. Meas., 1992, 41, 29.

48 R. Che, L. M. Peng, X. Duan, Q. Chen and X. Liang, Adv. Mater., 2004, 16, 401-405.

49 N. Li, Y. Huang, F. Du, X. He, X. Lin, H. Gao, Y. Ma, F. Li, Y. Chen and P. C. Eklund, Nano Lett., 2006, 6, 1141-1145.

50 A. P. Singh, A. Kumar, A. Chandra and S. K. Dhawan, AIP Adv., 2011, 1, 022147.

51 K. Singh, A. Ohlan, R. K. Kotnala, A. K. Bakhshi and S. K. Dhawan, Mater. Chem. Phys., 2008, 112, 651-658. 